\title{
Study on the Inter-organizational Information System Adaptation Mechanism Based on Organizaitonal Identification
}

\author{
Ming Yin ${ }^{1, a}$, Qi Liu ${ }^{2, b}$ and Zhanxing Zheng ${ }^{3, c}$ \\ ${ }^{1}$ School of Software and Microelectronics, Northwestern Polytechnical University, Xi'an, P.R China \\ ${ }^{2}$ The Air Force Equipment Research Ordering Department, Fuxing Road14, Haidian District, Beijing, \\ China \\ ${ }^{3}$ Hanzhong Branch, Aircraft Design and Research Institute of Xi'an Aircraft International Corporation, \\ Hanzhong, China \\ ayming@nwpu.edu.cn, byinming225@163.com, czhangxm182@163.com
}

Keywords: Inter-organizational Information System; Adaptation; Organizational Identification

\begin{abstract}
The adaptation mechanism of inter-organizational information system based on organizational identification remains under explored questions in the area of information system. In order to overcome the inadequacy of previous research, this paper firstly seeks to elaborate on the previous literatures of inter-organizational information system adaptation and organizational identification. Then the relationship between organizational identification and inter-organizational information system adaptation is analyzed. Finally, emphasis is placed on the theory model and hypothesises of inter-organizational information system adaptation based on organizational identification.
\end{abstract}

\section{Introduction}

With the repid development of economic globalization and information technique, information system has stepped across the boundary of organization and has been changed into complicated open inter-organizational information system from simple closed separate information system. The key problem of inter-organizational information system is how to adapt to internal and external environment $^{[1]}$. Inter-organizational information system (IOIS) is an integrated information system based on the complicated business collaboration relationship among different organization. The development of IOIS is limited to the inter-organization collaboration. IOIS adaptation is a very important problem. It is not easy for an enterprise to play a role of organizational system only depending on information technique. In order to get the advantage of IOIS, the enterprise should know how to manage interorganizational system from the point of organizational relationship.

Although there are many researches about system adaptation, there are few researches about inter-organizational information system, especially based on the theory of organizational identification. The achievements currently foucus more on traditional techniques. Therefore, it is significant to study IOIS and to IOIS adaptation based on organizational identification, which could provide decision foundation for the informationization practice of enterprises.

The remainder of the paper is structured as follows: In section 2, we review the previous literatures about organizational identification and inter-organizational information system adaptation. Section 3 shows the relationship between the two factors. Section 4 proposes the theory model and hypothesises accordingly. The paper rounds out with a conclusion and further research prospect.

\section{Literature Review}

Organizational Identification. Ghoshal and Gratton ${ }^{[2]}$ believe that companies are now improving integration in order to achieve the benefits of better sharing and coordination across those units after having captured benefits from strengthening the competitiveness of each unit. With the research of supply chain and dynamic alliance, cooperation among enterprises is more inseparably close than 
ever. Enterprises need Horizontal integration to achieve cooperation and profit. Organizational identification is that self-degree used to define organization attributes by members of organization ${ }^{[3]}$.

Organizational identification is a very difficult problem for dispersive business unit or standalone profit center. Recent researches are more focusing the high value member of organizational identification. Pratt and Foreman ${ }^{[4]}$ believed that one organization always had several identity. They presented that organization had several identity when primary idiomatical enduring concept appeared. However, there are still lack of researches on organizational identification in the process of multi-organizaiton cooperation.

Inter-organizational Information System Adaptation. In recent years, academic community pay more and more attention to the basic problem of inter-organizational information system. Kaufaman, who investigated the problem at the earliest, believed that adaptation of the information system stepping across organizations' boundary ${ }^{[5]}$. Barrett and Konsynski ${ }^{[6]}$ believed that integrated information system stepping across organizations' boundary had different interesting characteristics. These interesting and different ideas lead to different kinds of research topic. The researches on inter-organizational information system adaptation are always connected with implementation in the process of information system development. From 1960s to 1990s, existing many researches on information system implementation focus on technique factors. In that time, the researches about this problem is comparatively single. There exists a common cognition that information system implementation is a planning and rational process ${ }^{[7]}$. The researches on technique factors now are including the method and model of information system implementation ${ }^{[8]}$. In 1990s, researchers focused information system implementation more on the social shaping views ${ }^{[9]}$. In other word, information technique is the result of social action.

\section{The Relationship between Organizational Identification and Inter-organizational Information System Adaptation}

Currently, organizational identification is always regarded as a psychological and emotional ligament for individuals and organizations ${ }^{[10]}$. It is a process of defining self and belonging organization. If individuals have more acceptance of organization, they will think more and make behavior in an organizational perspective or make behavior conducive to the organization including more cooperation behavior and organizational citizenship behavior ${ }^{[3]}$. In the context of inter-organizational cooperation, the traditional theory of individual-organization identification has changed into the organization identification of organization-multiorganization alliance. From the point of informationism, organizational identification rests with the information communication among individuals and organizations. Information communication combines the sense of worth and purpose for information receiver with the ones for organizations in order to reduce the uncertainty of member. Patchen ${ }^{[12]}$ proposed that the dimensions of the inter-organizational information system can be divided into membership, loyalty, and similarity.

Inter-organizational information system is built to integrate several enterprises including up-and down-stream vendors, interrelated enterprises, and competitors and to cooperate for the competitive advantages. Recently, the researches about inter-organizational information system adaptation focus more on the social shaping views of technique in the process of organization transformation. Vasconcelos $^{[13]}$ studied the role of professional discourses in shaping the contexts upon which the organizational role of information systems is constructed and adapted. Liaskos et al. ${ }^{[14]}$ presented a requirements-driven approach to behavioral customization of software systems. Customization preferences posed at the requirements level were directly translated into system customizations. According to the viewpoint of software engineering, an information system adaptation is comprised by several dimensions. From the point of network, these dimensions are including technique adaptation, cooperation adaptation, and organization adaptation.

There exists relationship between organizational identification and inter-organizational information system adaptation. From what has been discussed above, we have knowned that both them have three dimensions. These dimensions interact in a certain way. From the experience of real 
practice, we may easily find that the influence of organizational identification on inter-organizational information system adaptation is very obvious. But membership, loyalty, and similarity, as dimensions of organization identification may have different affect on technique, cooperation, and organization adaptation, dimensions of inter-organizational information system adaptation.

\section{Theory Model and Hypothesises}

Fig. 1 shows the relation between organization identification and inter-organizational information system adaptation. Membership is subsidiary sense and emotion attraction of one organization to another. It is origined from the treasure behavior to members' relation and pride of organization. Loyalty is origined from the support of one organization to another. Similarity is origined from the understanding of organization's common characteristics. These three dimensions all have positive effect on the dimensions of inter- organizational information system adaptation. We can see the relationships are in the following Fig. 1. The sign of "+” shows the positive relationship from one factor to another. According to the theory model, we can easily work out the 9 hypothesises.

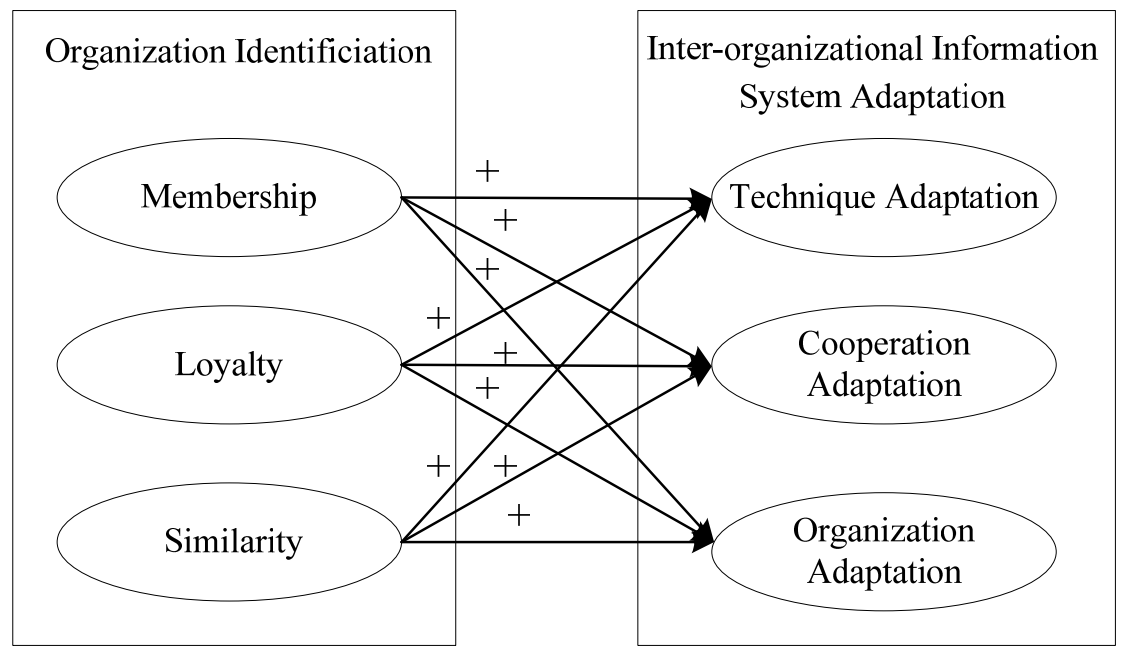

Fig. 1 Theory Model

Hypothesis 1 Membership has positive effect on technique adaptation.

Hypothesis 2 Loyalty has positive effect on technique adaptation.

Hypothesis 3 Similarity has positive effect on technique adaptation.

Hypothesis 4 Membership has positive effect on cooperation adaptation.

Hypothesis 5 Loyalty has positive effect on cooperation adaptation.

Hypothesis 6 Similarity has positive effect on cooperation adaptation.

Hypothesis 7 Membership has positive effect on organization adaptation.

Hypothesis 8 Loyalty has positive effect on organization adaptation.

Hypothesis 9 Similarity has positive effect on organization adaptation.

\section{Conclusion and Further Research Prospect}

Although researchers have studied information system adaptation in the past, they mainly focus on technique. There are few researchers emphasize on the study of inter-organizational information system adaptation. As an exploration for information system adaptation, although this research has achieved important conclusion, this paper still has inevitably existed certain limitation. This paper showed theory model and hypothesises of inter-organizational information system adaptation based on organizational identification while not having verification to assure the certainty of conclusions. Therefore, it is of great significance to further study the verification of relationship between organizational identification and inter-organizational information system adaptation. Therefore, it will be the further task of our research. 
This study not only handles problems of inter-organizational information system adaptation from a new perspective, but also provides researchers with insight about adapting the information system. We also hope that the discussion provides initial guidance and advice.

\section{Acknowledgment}

The author thanks all persons who involved in the research project. The researchers who are listed in the references are also need to be thanked greatly because of the fundamental work. We also thank for the support of National Natural Science Foundation of China (71201124, 71172124, 71102087), Humanities and Social Science Foundation of Ministry of Education of China (09YJC630188), National Scholarship Fund (201203070070), Research Fund for the Doctoral Program of Higher Education of China (20116102110036), Science and Technology Project of Shaanxi Province (2012k06-39), Humanities and Management Science Foundation of Northwestern Polytechnical University (RW201111). We appreciate the work of the editors on the paper.

\section{References}

[1] J. Y. Yan, B. Xu. The influence of interorganizational system on the relationship among cooperating organizations. China Soft Science, 2005, (3), pp. 117-125.

[2] S. Ghoshal, L. Gratton. Integrating the enterprise. Sloan Management Review, 2002, 44(1), pp. 31-40.

[3] J. E. Dutton, J. M. Dukerich and C. V. Harquail. Organizational images and member identification. Administrative Science Quarterly, 1994, 39(2), pp. 239-263.

[4] M. G. Pratt, P. O. Foreman. Classifying managerial responses to multiple organizational identities. Academy of Management Review, 2000, 25(1), pp. 18-42.

[5] F. Kaufman. Data systems that cross company boundaries. Harvard Business Review, 1966, 44(1), pp. 97-103.

[6] S. Barrett, B. Konsynski. Inter-organization information sharing systems. MIS Quarterly, 1982, 6(2), pp. 93-105.

[7] T. H. Kwon, R. W. Zmud. Unifying the fragmented models of information systems implementation. In Boland RJ, Hirschheim RA. (Eds.), Critical Issues in Information Systems Research, 1987, pp. 227-251.

[8] M. Heyouni, H. Sadok. A new implementation of the CMRH method for solving dense linear systems. Journal of Computational and Applied Mathematics, 2008, 213(2, 1), pp. 387-399.

[9] K. Horton, E. Davenport, Wood-Harper A. Exploring socio-technical interaction with Rob Kling: Five big ideas. Information Technology and People, 2005, 18(1), pp. 50-67.

[10] B.E. Ashforth, F. Mad. Social identity theory and the organization. Academy of Management Review, 1989, 14, pp. 20-39.

[12] M. Patchen. Participation, Achievement and Involvement on The Job. Englewood Cliffs, NJ, 1970.

[13] A. C. Vasconcelos. The role of professional discourses in the organizational adaptation of information systems. International Journal of Information Management, 2007, 27(4), pp. 279-293.

[14] S. Liaskos, S. M. Khan, M. Litoiu, M. D. Jungblut, V. Rogozhkin, J. Mylopoulos. Behavioral adaptation of information systems through goal models. Information Systems, 2012, 37(8), pp. 767-783. 